\title{
Espinoza, F. (2015). Bolivia: La Circulación de sus Élites (2006-2014). Santa Cruz de la Sierra: Editorial El País.
}

\author{
Carla Cisternas Guasch \\ Universidad de Santiago de Chile \\ carla.cisternas@usach.cl
}

Bolivia: La Circulación de sus Élites (2006-2014) emana de la tesis doctoral defendida por Fran Espinoza en el programa de Estudios Internacionales e Interculturales de la Universidad de Deusto, España. La investigación ofrece un novedoso análisis de la política boliviana a partir de la teoría de élites, específicamente sobre el proceso de la circulación de estas a partir del ascenso de Evo Morales al poder en 2006. Principalmente se analiza la composición social de las nuevas autoridades gubernamentales, así como su comparación y relación con la vieja élite económica. A raíz de esto, se ahonda en el estudio de las élites sectoriales vinculadas a la nueva élite política: cholas y cocalera ${ }^{1}$, como grupos aliados; y cruceña ${ }^{2}$, como grupo opositor. La investigación toma en cuenta aspectos del origen, composición social, trayectorias y simbolismos, lo que entrega una completa caracterización de las élites bolivianas.

La principal contribución de este libro es el análisis desde la teoría de las élites de un grupo que tradicionalmente es excluido del concepto clásico de élite. El estudio del gobierno de Evo Morales inició un recambió elitario y un nuevo ciclo político, el que es estudiado principalmente desde el enfoque de los movimientos sociales. De hecho, como lo señala el autor, hasta la aparición de este libro, no existían trabajos publicados que analizaran al Movimiento al Socialismo (MAS) como una nueva élite política en el poder. Junto a esto, otro aporte del trabajo es la definición de seis grupos elitarios para el análisis de circulación: contra-élite, vieja élite política, nueva élite política, élite sectorial cocalera, élite sectorial chola y élite cruceña.

1 El autor denomina élite sectorial chola a la comunidad conformada por los comerciantes aymaras y quechuas dedicados principalmente a la economía informal; y élite sectorial cocalera, al grupo cuya actividad principal es la producción y comercialización de la hoja de la coca, que apoya políticamente a Evo Morales y que se ha visto beneficiado por su administración.

2 El autor denomina élite cruceña al grupo asentado en Santa Cruz de la Sierra, conformado por la élite económica y sus redes familiares locales y extranjeras, caracterizados por poseer grandes extensiones de tierras. 
Antes del primer gobierno de Morales, Bolivia experimentó 20 ańos de una aparente estabilidad política y social derivada de los pactos políticos entre los partidos. Esta permanencia de la élite en el poder generó un importante rechazo a los gobiernos y partidos políticos tradicionales, contexto en el cual adquirieron fuerza los movimientos sociales, específicamente fueron clave la Guerra del Agua ${ }^{3}$ en Cochabamba el 2000 y la Guerra del Gas ${ }^{4}$ en La Paz el 2003.

La figura de Evo Morales como líder político surgió en 1997 cuando fue electo diputado representando a Izquierda Unidad (UI) apoyado principalmente por los sectores sindicales. Morales se caracterizó por ser opositor, crítico de la élite política y contrario al neoliberalismo y capitalismo. En 2005 fue electo presidente de Bolivia, instalando el primer gobierno con un origen político y social diferente al de la élite política boliviana histórica: un presidente sindicalista e indígena, y un gabinete ministerial compuesto por los líderes colonizadores ${ }^{5}$, cooperativistas, mineros, campesinos, indígenas, obreros, líderes de las juntas vecinales y mujeres trabajadoras que dirigieron la protesta social en Bolivia.

El libro de Espinoza analiza casi diez años de circulación de las élites desde que Evo Morales asume como presidente en 2006 hasta $2014^{6}$. El libro se estructura en siete capítulos para dar respuesta a dos hipótesis centrales: la primera $\left(\mathrm{H}_{1}\right)$, plantea que "Con el proceso de circulación de élites, los altos cargos del Estado boliviano están siendo administrado por representantes de los sectores sociales que habían estado excluidos del quehacer político, económico y social del país"; y la segunda $\left(\mathrm{H}_{2}\right)$ sostiene que "La vieja estructura de poder económico obligó a la nueva élite política

3 Se conoce como La Guerra del Agua a la protesta social de abril del 2000 en Cochabamba contra la empresa privada Aguas que suministraba el agua potable y alcantarillado de la zona. La manifestación se originó debido a un aumento en las tarifas del servicio y, tras varios días de movilización y enfrentamiento entre manifestantes y policías, logró expulsar a la compañía del sector.

4 La Guerra del Gas fue una movilización que ocurrió en octubre de 2003 y que congregó a miles de personas que protestaron en contra de la exportación de gas natural a Chile y a la posibilidad de que Bolivia ingresara al Área de Libre Comercio para las Américas (ALCA). La violencia de la protesta fue tanta que logró que el presidente Gonzalo Sánchez de Lozada renunciara a su mandato.

5 Campesinos cocaleros que se trasladaron a la región tropical amazónica de Chapare.

6 Se consideró el año 2014 pues a la fecha de la investigación el gobierno de Evo Morales aún se mantenía en el poder. 
a pactar con élite cruceña”. $\mathrm{H}_{1}$ se trabaja temporalmente desde 2006 a 2013, mientras que $\mathrm{H}_{2}$ se divide en dos fases: 2006-2009 y 2010-2014. Además de estas dos hipótesis, el autor se plantea otra serie de hipótesis específicas a lo largo de los diferentes apartados.

El primer capítulo ofrece una descripción de la metodología utilizada y un marco teórico sobre el estudio de las élites. Con respecto al marco metodológico, se señala el uso de técnicas mixtas: por un lado, a nivel cuantitativo, encuestas a ciudadanos de diversos perfiles (100 en Santa Cruz de la Sierra y 100 en La Paz); por otro lado, a nivel cualitativo, 31 entrevistas semiestructuradas aplicadas a reconocidos líderes de diferentes sectores y expertos sobre Bolivia, además de dos grupos focales.

Para la identificación y análisis de la élite política se utilizó las tres estrategias de estudio trabajadas ampliamente por Putman (1976): análisis posicional, análisis de reputación, y análisis decisional. Para el análisis de las posiciones de poder Espinoza utilizó el Decreto Supremo N. ${ }^{\circ} 29.894$ del 7 de febrero de 2009, que establece la nueva organización administrativa del Estado Plurinacional de Bolivia ${ }^{7}$.

Lo anterior se profundizó con el estudio de las relaciones informales, como vínculos de amistad o parentela (análisis reputacional) y el estudio de agentes influyentes en decisiones políticas (análisis decisional). El capítulo contempla una resumida revisión clásica sobre movimientos sociales, partidos políticos y el estudio de las élites en América Latina. Más originalmente se plantea el estudio de las élites en Bolivia, el cual se describe como escaso y poco actual. Los primeros trabajos señalan a las élites bolivianas como funcionales a los intereses extranjeros, desnacionalizadas y responsables de la discriminación y exclusión de indígenas, campesinos y mineros. Posteriormente, investigaciones a partir de la mitad del siglo XX, las describen como élites pactistas, asentadas en el poder y beneficiarias de la élite económica. Sobre las élites sectoriales, se describe a las viejas élites como el resultado de la reproducción de la herencia, el nivel socioeconómico y el prestigio; y, a las nuevas, como el resultado de capitales y procesos modernos (Donati 1991, Parson 1937).

Con respecto específicamente a la circulación de las élites, Espinoza se enfoca en la teoría clásica de Pareto (1987) que plantea que la circulación

7 Este decreto señala la nueva estructura de la administración pública, sus funciones y los valores y principios que deben tener los funcionarios públicos. Junto a esto, establece la creación de 15 ministerios, delimita el centro de apoyo gubernamental al presidente y describe las tareas y atribuciones del presidente y su gabinete. 
ocurre por el surgimiento de una contra-élite que pretende acceder al poder. Para este análisis se utilizó el modelo de circulación de Kolabinska (1912), el cual plantea que el fenómeno ocurre por el reemplazo total de las élites (recambio) o por la renovación de élites (movilidad social). Por las características de Bolivia, específicamente de la nueva élite a examinar, el análisis es complementado con el trabajo de Recce (2009), el cual señala que una contra-élite puede surgir por dos situaciones: 1) por mala asimilación histórica, es decir, debido a la exclusión social y étnica en la formación de los Estados nacionales; y 2) por mala asimilación reciente, causada por la exclusión de nuevos grupos culturales que han penetrado en sociedades ya constituidas. Para el caso boliviano, el autor utiliza el primer enfoque pues conceptualiza al MAS como una contra-élite excluida históricamente en la colonización y formación del Estado nacional boliviano, lo que generó abandono y pobreza de un sector social que, posteriormente, tomó conciencia de su condición, se organizó, demandó cambios al Estado y finalmente intentó disputar el poder.

El segundo capítulo analiza las causas de la circulación de las élites en Bolivia a través del uso del concepto de contra-élite. Para defender el concepto, el autor se propone la siguiente hipótesis específica: "La contraélite liderada por Evo Morales no solo defendía el uso tradicional de la hoja sagrada, denunciaba los efectos de las políticas neoliberales, los pactos entre la vieja élite política o la exclusión histórica, sino que también realizó cálculos políticos para acceder al reparto de poder en el aparato estatal".

El capítulo concluye que la circulación se debió a dos situaciones. Primero, al desgaste de la vieja élite debido a su comportamiento en los procesos de democratización e implementación del neoliberalismo en Bolivia. Segundo, al surgimiento de la contra-élite, cuyos orígenes se remontan a la histórica exclusión por parte del Estado boliviano a diferentes etnias, lo que sumado a la situación anterior, reforzó la sensación de abandono de los sectores marginados y de privilegio de las élites económicas.

La situación anterior, impulsó durante la década de los ochenta la organización social de estos sectores debido a la pobreza estructural del país y los conflictos con el Estado boliviano y Estados Unidos por la producción de la hoja de coca. El liderazgo político de Evo Morales surgió durante este periodo como dirigente sindicalista e indígena, con un discurso en defensa de la igualdad de los grupos marginados y en contra de la élite boliviana y Estados Unidos. Posteriormente, en la década de los noventa, el movimiento social no solo se organizó para la protesta social sino que decidió también disputar cargos de poder político. Es aquí donde el movimiento social se comenzó a configurar como una contra- 
élite adquiriendo un comportamiento de instituciones corporativas, negociando y repartiendo cuotas de poder para formar una alianza electoral entre movimientos sociales diversos, lo que le permitió ganar alcaldías, concejalías, escaños parlamentarios y, finalmente, la elección presidencial de 2005. Espinoza señala que el triunfo electoral se debió a una doble estrategia en la calle y en la vía institucional pues a mayor radicalización de la protesta social, principalmente por la Guerra del Agua en 2000 y la Guerra del Gas en 2003, mejores fueron los resultados electorales.

El tercer capítulo estudia los efectos de la circulación de las élites a ocho años del reemplazo abrupto de la vieja élite política por la nueva. El desarrollo de este capítulo pretende observar si son los sectores sociales -principalmente representados por los líderes de la protesta socialquienes han conformado la nueva élite. Para esto, Espinoza presenta un estudio descriptivo basado en los nombramientos de los siete gabinetes ministeriales desde 2006 a 2013, lo que se complementa con otro trabajo sobre élites parlamentarias, un estudio sobre el patrimonio de los ministros y un análisis de percepciones ciudadanas sobre el poder y los gabinetes.

El autor muestra que, al asumir la nueva élite, si fueron los líderes de los sectores sociales quienes dirigieron las carteras del gobierno de Evo Morales, sin embargo, trascurridos los años, se produjo un descenso a tal punto que en 2013 solo tres ministros eran representantes de los sectores sociales, siendo la élite tecnócrata quien lideraba casi en su totalidad el gabinete. Esto se explica, según Espinoza, por tres circunstancias: 1) el bajo nivel educacional de los sectores sociales; 2) la transformación del liderazgo de Evo Morales, desde una necesidad de apoyo popular a manejar el Estado; y 3) como una estrategia de cooptación de la nueva élite debido a sus escasos capitales económicos. Espinoza es capaz de mostrar una discrepancia entre el discurso social del MAS y sus nombramientos en cargos de poder político.

El cuarto capítulo aborda la construcción del nuevo Estado, específicamente desde el poder simbólico de Evo Morales, el cual apela a un discurso de integración de los sectores excluidos, la lucha por las reivindicaciones sociales y la revalorización de los pueblos indígenas, principalmente de los aymaras. El autor busca determinar si la construcción del nuevo Estado Plurinacional es parte del simbolismo o si se constituye verdaderamente como un proyecto político transformista.

En primer lugar, se afirma que el simbolismo es fundamental para la construcción del nuevo Estado como efecto de la circulación de las élites. La identificación de nosotros se forma en un sistema de creencias compartidas 
que, en término de Anderson (1993), apela a la autorepresentación de nosotros y no-otros, es decir, al sentido de pertenencia de los sujetos con un sector de la sociedad. La retórica de nuestros símbolos, nuestra cultura, nuestro pueblo se exalta como forma de enaltecer al pueblo históricamente excluido, lo que fortalece la cohesión élite-masa y el discurso de autopercepción como no-élite. Aquello coincide con la idea de Bourdieu (1998) sobre los sistemas simbólicos producidos y apropiados por un grupo, en este caso, generado por la élite gubernamental boliviana y reproducido por los sectores sociales afines al gobierno, creando una imagen de relaciones horizontales entre élite y sociedad, lo que es fundamental pues su poder electoral recae precisamente en aquellas bases sociales. Esto permite explicar la divergencia entre el discurso social y los nombramientos tecnócratas, pues el activismo de defensa del simbolismo y del gobierno -tanto en las instituciones como en la calle-impide que se cuestionen dichas actuaciones. De esta forma es aceptado y defendido que el ingreso a cargos de poder sea por experiencia -en el caso de los tecnócratas y la antigua élite- o por afiliación al MAS. En esta línea, el autor profundiza en los nombramientos y señala que el marco jurídico para designar a sujetos en posiciones de poder es favorable para la élite gubernamental ya que los cargos de niveles superiores, es decir, ministros, viceministros y directores son designados por el gobierno, lo que incluye también a sus asesores o personas que realicen funciones administrativas de confianza.

Para finalizar el capítulo, Espinoza realiza un estudio sobre las percepciones de la construcción del Estado Plurinacional y reconoce una voluntad del gobierno por cambiar la estructura del país, sin embargo, en términos de políticas públicas señala que no se distinguen grandes cambios. El Estado Plurinacional se percibe como parte del simbolismo de la élite a través de un discurso de inclusión social pero no en mejoras de la calidad de vida ni disminución de la pobreza.

El capítulo cinco ahonda en el estudio de las élites sectoriales, específicamente en la élite cocalera y chola, con el fin de evidenciar como se han desarrollado las relaciones entre las élites de los sectores sociales y el gobierno. Primero se estudia a la élite cocalera con la siguiente hipótesis: "La convergencia de intereses entre la élite sectorial cocalera y la élite política está representada en la figura política y social de Evo Morales”. El autor es capaz de confirmar aquella hipótesis por una serie de puntos que demuestran la cercanía entre Evo Morales y los cocaleros. Por ejemplo, desde hace 18 años que Morales es presidente de las Seis Federaciones de Cocaleros del Trópico de Cochabamba, es decir, ha mantenido su actividad como sindicalista siendo aún presidente. Esto tuvo como efecto que, al producirse la circulación de las élites, la producción de la coca pasara de 
ser estigmatizada a símbolo de identidad y lucha de la nueva élite, incluso, se creó la figura de Viceministerio de la Coca y Desarrollo Integral cuya función es desarrollar la producción de la hoja de coca como mecanismo para la reducción de la pobreza.

Con respecto a la élite chola, Espinoza sugiere que "La emergencia de la élite sectorial chola se debe a sus estrechas redes familiares y sociales de comercialización y a las ambivalencias del proceso de cambio". A diferencia de la élite sectorial cocalera, la relación de la élite política y la élite chola es más difusa e inestable. En primer lugar se evidencia una importante visibilidad económica y social debido a la expansión de sus redes dedicadas al comercio informal en el territorio y al aumento de su capacidad de venta y exportación de productos nacionales. En segundo lugar, se evidencia una escasa visibilidad política, lo que se explica por su intención de no politizarse con el fin de resguardar sus transacciones internacionales. De esta forma, la élite chola ha generado vínculos más sutiles con la élite política, por medio del financiamiento a campańas electorales del gobierno y la ocupación de algunos cargos en el Estado. Espinoza seńala que no es posible distinguir que tipo de relación mantienen ambas élites, lo que si se puede observar es que se necesitan mutuamente.

En síntesis, el autor concluye que la élite cocalera se origina en el ámbito político y presenta importantes redes en el ámbito económico y simbólico, mientras que, por otro lado, la élite chola surge en el ámbito económico con fuertes redes en el ámbito simbólico pero escasa presencia en el ámbito político. A pesar de sus diferencias, ambas élites coinciden en la defensa de sus intereses sectoriales.

Los capítulos seis y siete estudian a la élite sectorial cruceña. El capítulo seis pretende describir el perfil social de esta élite analizando su origen, redes familiares, principales actividades económicas, intereses y simbolismos. El análisis caracteriza a la élite cruceña como un grupo cuya riqueza se construye en torno a la posesión de tierras, con muchos vínculos comerciales con empresas extranjeras, consolidada y fortalecida por los lazos familiares, particularmente de matrimonio entre locales y europeos, $y$ con un simbolismo construido en el prestigio social y el poder económico, el cual configura un nosotros que representa la cultura de la camba ${ }^{8}$ y los problemas como región oriente.

8 Se denominan cambas a las familias tradicionales de Santa Cruz que se localizaron en la zona central de la ciudad. 
Espinoza atribuye la consolidación de la élite cruceña a tres causas: 1) las redes familiares que, según Espinoza, son cerca de 100 las que controlan la mitad de Bolivia a través de la industria, el comercio exterior, la banca y los medios de comunicación; 2) la cohesión y control de las instituciones económicas de oriente, entre ellas la Cámara de Industria, Comercio, Servicios y Turismo de Santa Cruz (CAINCO), la Cámara Agropecuaria del Oriente (CAO) y la Federación de Ganaderos de Santa Cruz (FEGASACRUZ); 3) el control de las instituciones políticas de oriente, principalmente del Comité Cívico Pro Santa Cruz, el cual actúa como intermediario frente al Estado y que ha logrado instalar una demanda autonómica por parte de la región la que incluso intentó derrocar a Evo Morales.

El capítulo siete analiza los efectos de la circulación de las élites y presenta las conclusiones finales. Para esto, el autor divide el proceso en dos fases: el reacomodo (2006-2009) y el pacto entre las élites (2010-2014). El reacomodo está compuesto por la ola de crisis políticas entre la nueva élite y la élite cruceńa, caracterizada por el auge de la demanda autonómica, el sentimiento de amenaza de la élite cruceña y el quiebre regional debido al alto nivel de polarización alcanzado en la población. Por otro lado, la fase del pacto entre las élites se caracteriza por el cese de las pugnas políticas, lo que según Espinoza se debe a un acuerdo entre los grupos elitarios: la élite ofreció a la élite cruceña estabilidad económica y apertura a nuevos mercados con el fin de calmar la crisis y mantenerse estable en el poder.

Respecto a sus hipótesis iniciales, Espinoza descarta la administración del Estado boliviano por los sectores sociales $\left(\mathrm{H}_{1}\right)$, pues se observa que, en general, los perfiles sociales del gabinete no coinciden con los de aquel sector. Para el autor, la baja en la participación de los sectores sociales en cargos gubernamentales se debe a tres factores: 1) su bajo nivel educacional y pobre experiencia en el manejo del Estado; 2) la consolidación de la élite tecnócrata calificada; y 3) el cambio en la estrategia de élite política. Sobre los dos primeros factores, una reflexión de Espinoza sugiere que el sistema educativo es aquel que obstaculiza y frena la circulación de las élites. Lo que sugiere entonces es que en el caso boliviano la vieja élite tecnócrata funciona a través de "círculos clientalares", reproducidos por su entorno familiar, afianzados durante su educación universitaria y cimentados con el ingreso al aparato estatal. Del factor de la estrategia política se señalan los pactos con la élite cruceña, la cooptación de miembros de la vieja élite política y la relación de privilegio con las élites sectoriales afines al gobierno. Este sistema de prácticas es denominada por el autor como un "sistema clientelar de élites" basado en relaciones utilitaristas de beneficios e intereses sectoriales que funciona de manera intermitente según el 
conflicto social y que asegura, en término de la teoría clásica de élites, que no surjan grupos antagónicos que quieran disputar el poder y producir una nueva circulación de élites.

Con respecto a la segunda hipótesis, Espinoza confirma la existencia de un pacto político entre la élite cruceña y la nueva élite política debido a la histórica estructura de poder económica boliviana que forzó un acercamiento entre ambas para fines sectoriales. Lo anterior se evidencia por el buen momento económico de la élite cruceńa y su buena relación con la élite política de Morales. El autor finaliza el libro siendo crítico del discurso no-élite de Evo Morales y su administración, el cual demuestra utiliza de forma exagerada la retórica y los simbolismos sin generar, en términos de las relaciones de poder, cambios muy significativos. Si bien se puede apreciar una circulación de las élites debido al acceso al poder de un sector históricamente excluido, y con esto un cambio en la estructura de poder, aún se mantiene la pobreza, la exclusión social y la desigualdad. Por el contrario, los índices económicos de la élite cruceña han aumentado significativamente lo que mantiene y profundiza el elitismo y el status quo.

En síntesis, Bolivia: La Circulación de sus Élites (2006 - 2014) realiza un importante aporte al estudio de las élites políticas latinoamericanas, particularmente al de la circulación de las élites. El caso boliviano resulta bastante original de estudiar pues el gobierno de Evo Morales históricamente ha renegado de su condición de élite.

Otro aporte del trabajo de Espinoza es la temporalidad de la investigación pues permite observar el caso como un proceso, entregando así una visión completa del fenómeno de la circulación, lo que evita conclusiones apresuradas sobre el ascenso al poder de los sectores sociales. Por un lado, la llegada al poder del MAS muestra un recambio completo e histórico de la élite política boliviana, sin embargo, con el paso del tiempo es posible observar un comportamiento cercano a la teoría clásica de élites, lo que se advierte en la baja renovación y la disminución del poder de los sectores sociales.

Por último, es interesante el trabajo que se realiza en torno al simbolismo, ya que permite explicar el poder que tiene el gobierno entre las bases sociales aun cuando no se evidencian mejoras sustantivas en la calidad de vida los sectores bolivianos excluidos. 


\section{REFERENCIAS}

Anderson, B. (1993). Comunidades Imaginadas. Reflexiones sobre el Origen y la Difusión del Nacionalismo. México: Fondo de Cultura Económica.

Bourdieu, P. (1988). Especio social y poder simbólico. Revista de Occidente, 81, 97-119.

Donati, P. (1991). Teoría Relazionale della Società. Milán: Franco Angeli.

Kolabinska, M. (1912). La Circulation des Elites en France. París: Beautiran.

Pareto, V. (1987). Escritos sociológicos. Madrid: Alianza Editorial.

Parsons, T. (1937). The Structure of Social Action. Nueva York: Free Press.

Putman, R. (1976). The Comparative Study of Political Elites. Nueva Jersey: Prentice Hall.

Recce, J. (2009). Poder Plástico: El Hombre Simbólico-Materialista y la Politica Internacional. Buenos Aires: Instituto de Publicaciones Navales. 